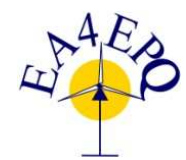

International Conference on Renewable Energies and Power Quality (ICREPQ'13) Bilbao (Spain), 20 ${ }^{\text {th }}$ to $22^{\text {th }}$ March, 2013

Renewable Energy and Pourer Qualiny. Fournal (RE\&PQJ)

ISSN 2172-038 X, No.11, March 2013

\title{
Application of Differential Evolution as method of pitch control setting in a wind turbine
}

\author{
F. Oterino-Echavarri ${ }^{1}$, E. Zulueta ${ }^{2}$, J. Ramos-Hernanz ${ }^{3}$, I. Calvo ${ }^{2}$ and J.M. Lopez-Guede ${ }^{2}$ \\ ${ }^{1}$ Department of Electronic Technology, \\ E.U.I. Vitoria-Gasteiz, UPV/EHU \\ Campus of Araba - Nieves Cano, 01006 Vitoria-Gasteiz (Spain) \\ Phone/Fax number:+0034 945 4160, e-mail: f.oterino@ehu.es \\ ${ }^{2}$ Department of System Engineering and Automation, \\ E.U.I. Vitoria-Gasteiz, UPV/EHU \\ Campus of Araba - Nieves Cano, 01006 Vitoria-Gasteiz (Spain) \\ Phone/Fax number:+0034 945 4160, e-mail: ekaitz.zulueta@ehu.es \\ ${ }^{3}$ Department of Electrical Engineering, \\ E.U.I. Vitoria-Gasteiz, UPV/EHU \\ Campus of Araba - Nieves Cano, 01006 Vitoria-Gasteiz (Spain) \\ Phone/Fax number:+0034 945 4160, e-mail: josean.ramos@ehu.es
}

\begin{abstract}
.
This paper illustrates the use of Differential Evolution technique applied to the optimization of the parameters of a pitch control in a horizontal axis wind turbine with variable speed. The turbine is $100 \mathrm{KW}$ and optimized pitch control. This paper shows how the use of these optimization strategies allow to solve and adjust of control parameters using heuristic algorithms without serious restrictions.
\end{abstract}

\section{Key words}

Wind turbine, Pitch control, Differential Evolution.

\section{Introduction}

Actually, the wind Energy has become a major Energy source in Spain. For example, the percentage of electricity consumed from wind power in Spain in 2009 was 14.4\% [1]. The importance of companies engaged in the manufacture of such technology has grown strongly, is today one of the most dynamic sectors of the Spanish economy [2]. Due to the change of course toward distributed electricity generation, many manufacturers are developing small and medium wind power. These turbines are suitable for electrical self-supply applications, domestic or industrial as generation points close to the demand the energy generated is used mainly to supply local demand, while the excess that is not consumed is sold to the electricity grid.
One of the most complex issues of the design of a wind turbine is the mutual influence of the different phases of design. You cannot separate the mechanical design of the control algorithm, due to the great influence exerted on the efforts to support the wind turbine. Also, the control system needs to know certain mechanical and aerodynamic aspects. The control of a turbine must satisfy three main objectives:

1.-Maximizing the electric power produced. The control of a turbine should ensure the maximum power production to reduce costs of energy production and increase profitability of the turbine.

2.-The control of the rotational speed in the rotor. The wind turbine control must avoid rotor speeds that could induce high critical loads on the turbine structure.

3.-The reduction efforts on the structure. The control of a turbine should minimize regulatory activity, because an overly active control action, implies that the forces on the structure occur more frequently, which means greater structural fatigue on machine components and reduced life of the turbine.

Improving each objective causes reversal in the others, therefore, the task of tuning the parameters of the turbine control is very complex. The purpose of this study is to simplify the process of setting control parameters of a wind turbine, fulfilling the three objectives for the regulator said. 


\section{Modelling of the wind turbine}

To study the behaviour of a wind turbine and its power regulation or control, there are three fundamental aspects to be modelled:

1.-The aerodynamic performance of the blades, characterized mainly by the rotor power coefficient, $\mathrm{cp}$.

2.-The dynamic behaviour of the power train in the wind turbine

3.-The electrical behaviour of the generator and the power amplifier.

There are other aspects, which are least important from the point of view of control design of a wind turbine:

-The structural design of the rotor.

-The design of the tower.

The modelling of such mechanics is not necessary to make a complete study of the control in a wind turbine and they are modelled when looking for the design and sizing of the same, and should be treated with other methods.

\section{A. Wind Turbine Model}

The most important characteristic of the wind turbine is the power coefficient $\left(c_{p}\right)$ that defines the obtained wind power:

$P=\frac{c_{p} \cdot \pi \cdot v^{3} \cdot \rho_{\text {air }} \cdot R^{2}}{2}$

\begin{tabular}{|l|c|c|}
\hline & Definition & Units \\
\hline$P$ & Obtained power & W \\
\hline $\mathrm{V}$ & Wind Speed & $\mathrm{m} / \mathrm{s}$ \\
\hline$R$ & Blade Radius & $\mathrm{m}$ \\
\hline$\rho_{\text {air }}$ & Air density & $\mathrm{Kgr} / \mathrm{m}^{3}$ \\
\hline$c_{p}$ & Power coefficient & --------- \\
\hline
\end{tabular}

Table I. - Variables and constants' definition

The Power coefficient is a function of wind speed, pitch angle and angular speed. Is very usual to define a parameter called $\lambda$. This parameter establishes the relationship between the wind speed and the speed of the blade tip.

$$
\lambda=\frac{R \cdot w}{v}
$$

\begin{tabular}{|l|c|c|}
\hline & Definition & Units \\
\hline $\mathrm{v}$ & Wind Speed & $\mathrm{m} / \mathrm{s}$ \\
\hline$\beta$ & Pitch angle & $\mathrm{rad}$ \\
\hline $\mathrm{w}$ & Rotor angular speed & $\mathrm{rad} / \mathrm{seg}$ \\
\hline
\end{tabular}

Table II. -Variables and constants' definition

If defined $\lambda$ as a adimensional parameter that establishes the relationship between the wind speed and the speed of the blade tip, the surface of power coeficient can be traced as is shown in Figure 1

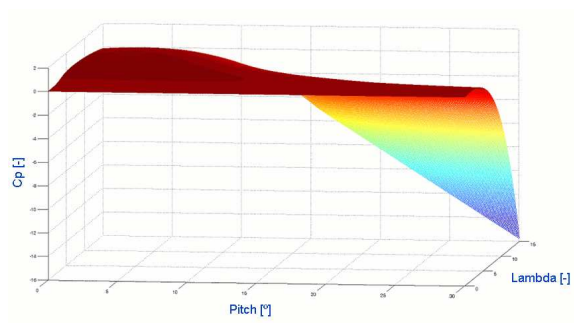

Figure 1: Surface of power coefficient.

In the following expression it can see the torque offered:

$T_{\text {Turbine }}=\frac{P}{w}=\frac{c_{p}(\lambda, \beta) \cdot \pi \cdot v^{3} \cdot \rho_{\text {air }} \cdot R^{2}}{2 w}$

\section{B. Power Train Model}

The power train model defined in this paper is the following one:

$$
T_{\text {Turbine }}-i T_{\text {machine }}=\left(i^{2} . J_{\text {machine }}+J_{\text {turbine }}\right) \frac{d w}{d t}
$$

\section{Power stage and electric generator model}

Due to the object of this paper is to design an wind turbine is not been considered the issues related to power electronics, the dinamic of the electric machine or the power grid. This is because the development of these power stages can be summarized from the wind turbine viewpoint as a first order system enabling establish a pair of machine with a given time constant. Such devices usually be acquired in established firms in this type of product [3]. From the viewpoint of the wind turbine constructor, must be studied only the ability to impose the turbine torque and the performance of this stage.

$$
\frac{d T_{\text {máquina }}}{d t}=\tau_{P E}\left(T_{\text {máquina }}^{*}-T_{\text {máquina }}\right)
$$

\begin{tabular}{|l|c|c|}
\hline & Definition & Units \\
\hline Tmachine & $\begin{array}{c}\text { Torque imposed by the } \\
\text { machine }\end{array}$ & $\mathrm{Nm}$ \\
\hline $\mathrm{T}^{*}$ machine & Torque set point & $\mathrm{Nm}$ \\
\hline $\boldsymbol{\tau}_{\mathbf{P E}}$ & Time constant & $\mathrm{seg}$ \\
\hline
\end{tabular}

Table III. - Variables and constants' definition

\section{D. wind speed model.}

The wind is a fundamental input variable to the model. For the correct wind model will use two terms:

1. The wind speed average. The wind speed average is modeled by speed profiles that depends on the height where we want to do the average

2. The turbulence: This term is modeled as a random process with a given spectre. For this term exist different models [4]. Many of these models are fixed in military standars [5].

In the case of our wind turbine model will use a stepwise wind. There are other more realistic wind models such as the Von Karman [6]. 


\section{Control structure}

The manipulated control variables are:

1. The torque setpoint requested by the power stage to the electric machine.

2. The pitch angle that is imposed to the turbine blades.

The controlled variable is the rotational speed of the rotor in the wind turbine. The proposed control strategy is mainly based on dividing the operation into two operating modes, power optimization and power regulation.

In the first mode, the control objective is to extract maximum energy from the wind as possible. This mode is associated with a range of speeds from the minimum speed to a speed somewhat lower than the nominal angular velocity.

In this first range of speeds is imposed on the electric machine a torque such that in permanent regimen the wind turbine give us the maximum power. If is wanted to achieve maximum power for a given wind speed, you must achieve the maximum power coefficient. This power coefficient have a maximum value for a particular pitch and $\lambda_{\text {optim. }}$. The optimum "pitch" angle is usually $0^{\circ}$ or an angle close to zero. In the case of $\lambda_{\text {optim }}$ will depend on the blade profile. Then the optimum torque can be defined as follows.

$$
\begin{aligned}
P_{\text {optim }}= & =\frac{c_{p, o p t i m} \cdot \pi \cdot v^{3} \cdot \rho_{\text {aire }} \cdot R^{2}}{2} \Rightarrow T_{\text {optim }}=\frac{P_{\text {optim }}}{w}=\frac{c_{p, o p t i m} \cdot \pi \cdot v^{3} \cdot \rho_{\text {aire }} \cdot R^{2}}{2 w} \Rightarrow \\
T_{\text {optim }} & =\frac{c_{p, o p t i m} \cdot \pi \cdot\left(\frac{R w}{\lambda_{\text {optim }}}\right)^{3} \cdot \rho_{\text {aire }} \cdot R^{2}}{2 w}=\frac{c_{p, o p t i m} \pi \cdot \rho_{\text {aire }} \cdot R^{5}}{2 \lambda_{\text {optim }}} w^{2}
\end{aligned}
$$

Assuming that at steady state there is no acceleration of the rotor, the torque must match with the torque of the electric machine, the latter being defined as:

$$
T_{\text {machine }}==\frac{c_{p, \text { optim }} \cdot \pi \cdot \rho_{\text {aire }} \cdot R^{5}}{2 . \lambda_{\text {optim }}^{3}} w^{2}
$$

For the transition between the first and second stages we will establish a straight line from speeds close to nominal speed to the rated speed of the turbine.

In the second operation mode, we will force them to absorb energy in the electric machine. This causes the torque is reduced in hyperbolic shape with respect to speed.

$$
T_{\text {machine }}=\frac{P_{\text {nominal }}}{i . w}
$$

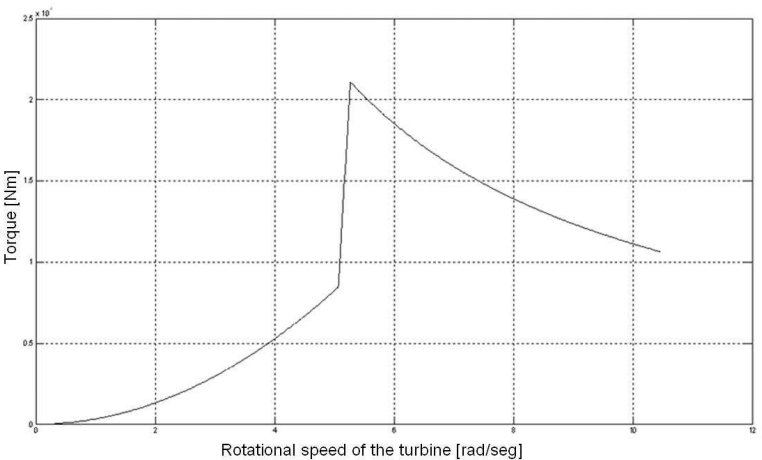

Figure 2: Torque imponed by the generator

In regard to the pitch angle control has been proposed a PI control, at which regulates the pitch angle. trying to keep the speed of rotor imposed. The output range can go from a value slightly lower than $0^{\circ}$ to a maximum value, the limit is $90^{\circ}$ in case of emergency stop. The maximum rate of change that is supported is 10 ${ }^{\circ}$ per second, which is the most appropriate speed to act on the blades. It is recalled that a slow change speed of "pitch" makes the blades are not able to continue properly to changes, which would endanger the installation. On the other hand, is not interesting a too rapid rate of change because it could cause excessive stresses on the structure.

With this type of control in the second mode will never have an overproduction from the viewpoint of the grid. It should be noted that changing the pitch angle of the blades involves load changes on them. Consequently, we tune controller so as to minimize as far as possible the pitch control activity fatigue with the purpose not in excess of the wind turbine structure.

The pitch PI regulator acts on the speed error of the rotor, defined as the difference between the rotor speed and the setpoint speed:

$$
\begin{aligned}
& \beta^{*}=K_{p}\left(\text { error }+\frac{1}{T_{i}} \text { error }_{\text {integral }}\right) \\
& \text { error }=w-w^{*} \\
& \text { error } r_{\text {integral }}=\left\{\begin{array}{c}
-L_{\text {integral }}:-L_{\text {integral }}>\int_{0}^{t} \text { error.dt } \\
\int_{0}^{t} \text { error.dt }: \quad-L_{\text {integral }}<\int_{0}^{t} \text { error.dt }<L_{\text {integral }} \\
L_{\text {integral }}: L_{\text {integral }}<\int_{0}^{t} \text { error.dt }
\end{array}\right.
\end{aligned}
$$

The proposed regulator has the following parameters: $\mathrm{Kp}$ and $\mathrm{Ti}$. The adjust of these parameters is often done with linear system theory because the behavior of the wind turbine is highly nonlinear, the pitch PI controller is tuned using linearized models of the turbine.The biggest problem with this kind of strategy is that the operating point varies greatly and therefore the parameters must be gradually adjusted. This technique is called "gain scheduling"[7]. The equations for the synthesis of the PI controller are as follows [8]. 


$$
\begin{aligned}
T_{i} & =\frac{2 \xi}{\omega_{n}} \\
K_{p} & =\frac{2 \xi}{\omega_{n}} \frac{K \Omega_{0}}{i \cdot \frac{30}{\pi}}\left(-\frac{\partial P}{\partial \beta}\right)^{-1}
\end{aligned}
$$

Donde:

$$
K=\omega_{n}^{2}
$$

$\xi$ and $\omega_{\mathrm{n}}$ are design parameters and the control engineer must set the apropiate value for them. Usually, these values are $\omega_{\mathrm{n}}=10[\mathrm{rad} / \mathrm{s}]$ y $\xi=0,66[-]$ [8] in $2 \mathrm{MW}$ wind turbines. $\Omega_{0}$ is the value of the rotational speed of the turbine around which the model is linearized.

In our case, this speed is equal to the rated speed. Finally, the term associated with the partial derivative of the power generated respect to "pitch" angle is function of this angle. Therefore, the gain must be changed depending on the value of the pitch angle.

\subsection{Control Adjusment}

In this paper, we propose to use an optimization algorithm to select the controller parameters, with the objective that the proposed cost function (13) will be minimal. The algorithm proposed in order to minimize a given cost function is known as Differential Evolution algorithm. A proper development to understand this optimization algorithm is in [9].

As mentioned above, to set a criterion of tuning control parameters, there are three important questions:

-The amount of electric power that is injected into the network. This variable depends on the time which is common to choose the period of one year as a reference. The optimization criterion is sought then is to maximize annual electricity production. Obtaining annual electricity production is done integrating the instantaneous power generated by the wind turbine for each wind speed of its operating range, according to the annual statistical distribution of each wind speed for a given location. Usually the probability distribution of wind speeds is described by the Rayleigh probability distribution.

- The error of the rotor speed. During operation at wind speeds above the rated wind speed, the target pitch control system is to maintain rotor speed constant at its rated speed. The error of the speed of rotation in the rotor occurs when it exceeds the rated speed of rotation. The speed of the rotor above its rated speed, involves increasing efforts on the structure. Even if it exceeds a certain angular speed limit can induce coupling problems that harm the turbine structure. Therefore, the goal of optimization is to minimize the error in the rotor speed.

- Efforts on the structure of the wind turbine. The pitch controller activity significantly influences on the structural fatigue of the machine, then the optimization algorithm seek to minimize the reactivity of the pitch system.

The efforts on the wind turbine depend of the aerodynamic interaction between the turbine aerodynamics and its structure, which are not easy to calculate. For such efforts specific aeroelastic tools are used [10].
The cost function is given below:

$$
\text { Cost }=\lambda_{1} P_{\text {avg }}+\lambda_{2} \text { Error }_{\text {speed }}+\lambda_{3} \text { Activity }_{\text {pitch }}
$$

Where $\lambda_{1}, \lambda_{2}$ and $\lambda_{3}$ are three terms with determinate weight, they are explained below.

The first term is the average power associated with the generated simulation:

$$
P_{\text {avg }}=\frac{1}{T_{\text {simulation }}} \int_{0}^{T_{\text {simulation }}} P . d t
$$

$\mathrm{P}$ is the generated power by the wind turbine, The average value is obtained over a period of time equal to the duration of the simulation. The most common simulation time is $300 \mathrm{~s}$. This mentioned value is the time horizon used, because it is considered a reasonable time with respect to time of response in wind turbines.

$$
\begin{aligned}
& \operatorname{Error}_{\text {Speed }}=\frac{1}{T_{\text {simulation }}} \int_{0}^{T_{\text {simulation }}} \operatorname{Error}_{W(\text { high })} . d t \\
& \operatorname{Error}_{W(\text { High })}=\left\{\begin{array}{c}
\left|w^{*}-w\right|: w>w^{*} \\
0: w<w^{*}
\end{array}\right.
\end{aligned}
$$

In the case of the term associated with the activity of the pitch, we define the following function.

$$
\text { Activity }_{\text {pitch }}=\frac{1}{T_{\text {simulacion }}} \int_{0}^{T_{\text {simulacion }}}\left|\frac{d \beta}{d t}\right| \cdot d t
$$

The fatigue is heavily dependent on rapid changes in pitch angle because the turbine bearing loads vary strongly with him. This makes that a control very "nervous" is not interesting for the installation, since it forces oversize the structure of the tower and the blades.

To finish completely define the cost function, it should be explained how they have chosen the weights of the three terms discussed above. The value assigned to parameter $\lambda_{1}$ is -10 , because must obtain the maximum average power. The negative sign of this parameter is because we want to minimize the cost function. The parameter associated with the average error of speed, $\lambda_{2}$ is assigned a value of 10 , because if this value is great, will be closer of the resonance point in the structure. Finally, the $\lambda_{3}$ parameter takes the value 1 , as compared to the other two terms are considered 10 times less important economically.

\subsection{Optimization algorithm: differential evolution}

The differential evolution algorithm is applied in optimization problems in which the cost function is not known and we can expect a large number of local minima. In fact, it is not necessary to achieve a cost 
continuous function or necessarily derivable. Such algorithms are relatively new concepts and make use of concepts very close to genetic algorithms. Such algorithms are based on the concept of swarm intelligence. They are being applied in fields like control systems as well as in areas such as system identification. The greatest feature of such algorithms is that it seeks to optimize a problem by calculating a cost function iterated so applied to a series of candidate solutions. In general such algorithms are known as metaheuristic. The differential evolution algorithm presents two disadvantages when they are applied to control problems

1.-The algorithm does not guarantee that the optimal solution is reached, and will be an suboptimal solution.

2.-It can not been applied this algorithm directly to solve problems that are on-line, as it requires to run in parallel the different solutions, and this issue is not acceptable for the control algorithms, since each currently only apply a single solution. It is for that reason only be applied to the control parameter adjustment so as to work off-line.

This algorithm can be summarized as follows:

1.-It initializes a set of possible candidate solutions:

The values are given with random methods within the possible range for each parameter that we want to optimize

We have $\mathrm{N}$ agents or candidate solutions

$$
\overline{x_{k}}=\left[\begin{array}{ll}
\varepsilon_{k} & \omega_{n, k}
\end{array}\right](17)
$$

As we can see, the " $k$ " variable takes values from 1 to $\mathrm{N}$. Obviously each one of these candidate solutions will take values around of the proposed in the scientific literature [2]. The central values for each parameter is taken as $\omega \mathrm{n}=10[\mathrm{rad} / \mathrm{s}]$ and $\xi=0.66[-]$. Due to the uncertainty about these values applied in a $100 \mathrm{KW}$ turbine, we have decided that the range of values between the maximum and minimum are $10 \%$.

2.- This loop is repeated in a determined number of times. The number of times can be reduced using stop criteria as getting an acceptable cost. In each loop must update all agents or candidate solutions.

2.1.- Repeat this loop for each agent.

2.1.1.- We will take 3 agents randomly without repetition

$$
\begin{aligned}
& \overline{x_{a}}=\left[\begin{array}{ll}
\varepsilon_{a} & \omega_{n, a}
\end{array}\right] \\
& \overline{x_{b}}=\left[\begin{array}{ll}
\varepsilon_{b} & \omega_{n, b}
\end{array}\right] \\
& \overline{x_{c}}=\left[\begin{array}{ll}
\varepsilon_{c} & \omega_{n, c}
\end{array}\right]
\end{aligned}
$$

2.1.2.-Generate a solution as a combination of the 3 above, called $r$.

$$
\bar{x}_{r}=\bar{x}_{a}+F\left(\bar{x}_{b}-\bar{x}_{c}\right)
$$

The parameter $\mathrm{F}$ is a value that is in the range [0,2]. With this parameter can be modulated the mutation capacity of the algorithm. This range is set to avoid that the solutions go out of the proposed range. To prevent this point. Also we will limit the maximum and minimum output values.

2.1.3.-With the " $r$ " agent and the agent that is being updated, we must generate another agent or candidate solution " $t$ ". The " $t$ " components are generated randomly with the " $r$ " agent or with the agent that is being updated. If the random number generated in the interval $[0,1]$ is greater than a parameter GR, then the component is taken from " $\mathrm{r}$ ", else from the agent that is being updated.

$$
\begin{aligned}
& \overrightarrow{x_{r}}=\left[\begin{array}{ll}
\varepsilon_{r} & \omega_{n, r}
\end{array}\right] \\
& \overrightarrow{x_{k}}=\left[\begin{array}{ll}
\varepsilon_{k} & \omega_{n, k}
\end{array}\right] \\
& \overrightarrow{x_{t}}=\left[\begin{array}{ll}
\varepsilon_{t} & \omega_{n, t}
\end{array}\right] \\
& \varepsilon_{t}=\left\{\begin{array}{r}
\varepsilon_{r}: \text { If } G R>\text { random }([0,1]) \\
\varepsilon_{k}: \text { Otherwise }
\end{array}\right. \\
& \omega_{n, t}=\left\{\begin{array}{r}
\omega_{n, r}: \text { If } \text { GR }>\text { random }([0,1]) \\
\omega_{n, k}: \text { Otherwise }
\end{array}\right.
\end{aligned}
$$

With the GR parameter, can modulate the ability of recombinant algorithm. This parameter is between 0 and 1.

2.1.3.- Finally we must evaluate the agent or candidate solution, and if the cost is less than the cost of "r" agent then, this agent is upgraded or replaced by the " $t$ " agent.

\section{Simulatión}

To support this section we performed the simulation of control of a small wind turbine installed in the Miñano Technology Park (Alava, Basque Country) designed by the company Argolabe Engineering, with the support of the Basque Government and the Ministry of Science and Innovation, and in collaboration with CIEMAT and others. This $100 \mathrm{KW}$ turbine is designed for applications in distributed generation and consumption, both domestic and industrial.

\section{A. Characteristics of the Wind turbine}

The most important characteristics of the turbine are:

1. Power Rating: $100(\mathrm{~kW})$

2. Inertia of the turbine: 28781: (Kgr.m2)

3. Inertia of the rotor in the electrical machine: 5.4 (Kgr.m2)

4. Curve of the blades, absolute optimum values of the surface of cp:

- $\mathrm{C}_{\mathrm{pmax}} 0.47$ (-)

- $\beta_{\text {optimo }} 0(\mathrm{rad})$

- $\lambda_{\text {optimo }} 6.5(-)$

5. Nominal speed which gives the nominal power of 100 kW: 50 (rpm)

6. Maximum rotational speed of the blades from which one runs the risk of coming into a resonance: 55 (rpm)

7. Reduction coefficient: 15 (-)

8. Total efficiency of the power stage of the electrical machine 0.9 (-)

9. Radius of the blade: $10(\mathrm{~m})$ 


\section{B. The wind speed was characterized as follows:}

1.-To control optimization has been proposed that the speed of wind behave step by step, in which each step remain for $60 \mathrm{~s}$. The initial speed is $5 \mathrm{~m} / \mathrm{s}$ and each increment is $5 \mathrm{~m} / \mathrm{s}$ ending at a wind speed of $20 \mathrm{~m} / \mathrm{s}$. The operating range of the pitch control system is from wind speeds of $10 \mathrm{~m} / \mathrm{s}$ until until the turbine is stopped by excessive wind speed $20 \mathrm{~m} / \mathrm{s}$. This stepwise wind profile [8] is very useful to evaluate the response of the controller.

The most relevant features and their respective control actuators are:

1. Rotational speed of the turbine from which starts the transition between two zones of operation: 48 (rpm).

1. Rotational speed of the turbine from which finish the transition between two zones of operation: 50 (rpm)

Parámetros de la función de coste:

$\lambda 1:-10$

$\lambda 2: 10$

$\lambda 3: 1$

Dynamic characteristics desired in linear regime with the PI control running.

- Time constant of the power stage of the electrical machine: 0.1 (s)

- Time constant of the valves that sets the pitch of the blade: $10(\% / \mathrm{s})$

- Maximum rate of change of valves: $10(\% / \mathrm{s})$

- Maximum angle of pitch in normal operation in the area of high speeds: 45 (degrees)

- Minimum angle of pitch in normal operation for both the area of high and low speeds: $0\left(^{\circ}\right)$

- Speed set point in high speed area. w 50 (rpm)

Features algorithm

-Number of agents: 100

-Number of iterations: 10

-F, mutation ratio: 0.5

-GR, recombination coefficient: 0.5

- Time horizon simulation- $\mathrm{T}_{\text {simulation }}: 300$ (s)

\section{Results}

In the figure 3, you can see the wind turbine operation at the optimum point, with the control parameters which have been obtained using the optimization algorithm. The optimum is achieved for $\omega_{n}=3.592$ and $\xi=0.594$, which is the point with minimum cost. In the first plot, we can see that the power is adjusted appropriately according to wind speed that has been imposed on the second plot. It can be appreciated that the power of $100 \mathrm{KW}$ is obtained when the wind speed is nominal. Also, you can see how the pitch angle gets adjusted to regulate the speed of rotation, as seen in the last plot which is the speed of rotation to speed in $\mathrm{rpm}$.

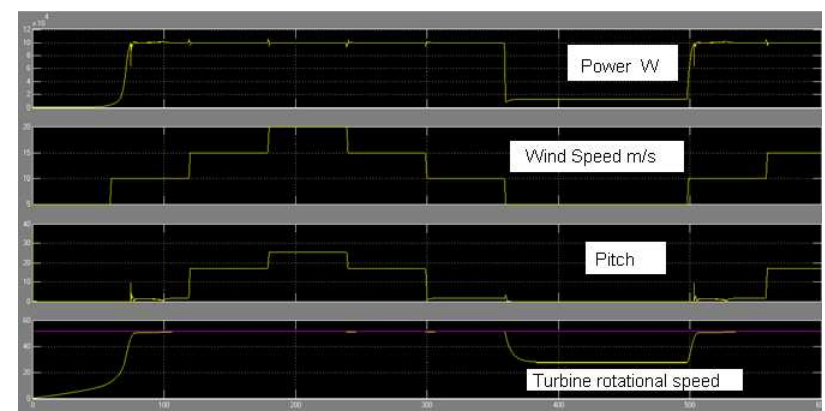

Figure 3: Behavior of the turbine to the optimal position achieved by differential evolution

\section{Conclusions and Future \\ A Conclusions}

The most important contribution of this paper is to propose a modeling able to calculate the most important aspects of the wind turbine control but simple enough so that it can be simulated in any simulation platform of dynamic systems.

The second conclusion is that with the results obtained with the simulation of the proposed model can be fedback to the different platforms directed to design different aspects of structural in a wind turbine tower.

Finally, as a final conclusion, the usefulness of optimization tools, such as differential evolution algorithm, to successfully perform the complex task of tuning the parameters of wind turbine control

\section{B. Future}

Currently they are working on the development of a model that integrates the above aspects with the variables that best define the structural behavior of a wind turbine.

Using this more general model is expected to perform the calculation of the turbine aeroelastic efforts [10].

On the other hand, is working on new wind turbine control strategies, because it could be proposed to make the comparison between different control strategies applied to the control of wind turbines.

\section{References}

[1] El sistema eléctrico español 09. [Alcobendas]: Red Eléctrica de España, 2010. p.31. Depósito legal: M-31202-2010

[2] De Otto S, Pérez A, et al. Anuario Eólica 2010. [Madrid]: Asociación Empresarial Eólica, 2010. p.45-47.

[3] Eichler M, "En el mar y en línea, Convertidor PCS 6000 para turbinas eólicas marinas de 5 MW". Revista ABB. 2008. Vol.3 p.56-61.

[4] Carta J A, Ramırez P, Velazquez S. "A review of wind speed probability distributions used in wind energy analysis Case studies in the Canary Islands". Renewable and Sustainable Energy Reviews. 2009. Vol.13. p.933-955.

[5] Department of Defense USA. Flying Qualities of Piloted Aircraft. MIL-HDBK-1797. 1997.

[6] Leidhold R, García G, Valla M I. "Control para máximo rendimiento de generadores eólicos de velocidad variable, con limitación de velocidad y potencia”.En: XIV Congresso Brasileiro de Automática, (Natal 2-5 de septiembre de 2002), 2002. p.3121-3122.

[7] Hansen M H, Hansen A, Larsen T J. Control design for a pitch-regulated, variable speed wind turbine. [Roskilde, Denmark]: Ris $\varnothing$ National Laboratory, 2005. p.47-48.

[8] Hansen M H, Hansen A, Larsen T J. "Control design for a pitch-regulated, variable speed wind turbine". [Roskilde, Denmark]: Ris $\varnothing$ National Laboratory, 2005. p.15-18. 
[9] Mitra P, Venayagamoorthy G K. "Artificial Immune System Based DSTATCOM Control for an Electric Ship Power System".

En: Proceddings of Power Electronics Specialists Conference,

(Rhodes 15-19 de junio de 2008), 2008. p.718-723.

[10] Jonkman J. FAST NWTC Design Codes.[en linea].<http://wind.nrel.gov/designcodes/simulators/fast/>

[Consulta: 22 de diciembre de 2010] 